\title{
IDENTIFIKASI KEJADIAN GASTRITIS PADA SISWA SMU MUHAMMADYAH 3 MASARAN
}

\author{
Eka Novitayanti \\ Program Studi Sarjana Keperawatan, STIKes Mitra Husada Karanganyar \\ Email : exanovita@gmail.com
}

\begin{abstract}
ABSTRAK
Gastritis merupakan masalah pencernaan yang sering terjadi pada remaja, kebanyakan menyerang pada mahasiswa dan siswa. Gastritis adalah peradangan pada mukosa lambung. Penelitian ini bertujuan Untuk mengetahui angka kejadian gasteritis pada SMU Muhammadyah 3 Masaran. Metode penelitian yang digunakan adalah penelitian observasional deskriptif. Populasi dalam penelitian adalah semua siswa SMU Muhammadyah 3 Masaran. Tehnik sample penelitian total sampling dimana seluruh anggota populasi dijadikan sampel. Hasil Identifiakasi kejadian gastritis di SMU Muhammadyah 3 Masaran dari 52 responden yang mengalami gastritis sebanyak 27 responden (51,9\%). Gastritis banyak di derita oleh siswa SMA yang tergolong remaja karena makan tidak teratur, sehingga akan menganggu aktivitas sehari-hari siswa SMU. Kesimpulan sebagian besar siswa SMU Muhammadyah 3 Masaran mengalami Gastritis. Penelitian ini menyarankan para siswa semakin tahu kejadian gastritis, penyebab dan tanda gejala sehingga dapat menghindari penyebab gastritis.
\end{abstract}

Kata Kunci: Kejadian, Gastritis

\section{ABSTRACT}

Gastritis is a digestive problem that often occurs in adolescents, mostly attacking students and students. Gastritis is inflammation of the gastric mucosa. This study aims to determine the incidence of gastricitis in Muhammadyah 3 Masaran High School. The research method used was descriptive observational research. The population in the study were all students of Muhammadyah 3 Masaran High School. The sample research technique is total sampling where all members of the population are sampled. Results Identification of the incidence of gastritis in Muhammadyah High School 3 Masaran of 52 respondents who experienced gastritis as many as 27 respondents (51.9\%). Gastritis is suffered a lot by high school students who are classified as teenagers because of irregular eating, so that it will disrupt the daily activities of high school students. Conclusion most of Muhammadyah 3 High School students in Masaran have gastritis. This research suggests students increasingly know the incidence of gastritis, causes and signs of symptoms so as to avoid the causes of gastritis.

Keywords: Occurrence, Gastritis

\section{PENDAHULUAN}

Pembangunan kesehatan saat ini dihadapkan pada dua masalah yaitu penyakit menular dan penyakit tidak menular. Penyakit tidak menular kebanyakan disebabkan oleh gaya hidup modernisasi dan globalisasi salah satunya penyakit gastritis (Monika, 2018). Masalah kesehatan pada saluran pencernaan yang paling banyak yaitu penyakit gastritis Gastritis merupakan gangguan kesehatan pada saluran pencernaan yang sering di jumpai di klinik berdasarkan gejala klinis bukan berdasarkan pemeriksaan hispatologi. Gastritis adalah proses inflamasi pada mukosa lambung dan sub mukosa lambung (Rizky, dkk, 2019).

Gastritis merupakan gangguan kesehatan terkait proses pencernaan terutama lambung. Lambung bisa mengalami kerusakan karena proses peremasan yang terjadi secara terus menerus selama hidupnya. Lambung bisa mengalami kerusakan jika sering kosong, karena lambung akan meremas hingga dinding lambung lecet dan luka, dengan adanya luka tesebut mengalami proses inflamasi yang disebut gastritis (Muhith\&Suyoto, 2016).

Kejadian penyakit gastritis disebabkan karena pola makan yang tidak sehat seperti konsumsi alkohol, pola makan yang tidak teratur, merokok, konsumsi kopi, konsumsi obat penghilang nyeri, stres fisik, stres psikologis, kelainan autoimun. Gejala yang timbul pada pasien gastritis adalah rasa tidak enak pada perut, perut kembung, sakit kepala, mual dan lidah berlapis (Wahyudi, dkk, 2018).

Gastritis dapat menyebabkan beberapa komplikasi penyakit. Penyakit yang timbul sebagai komplikasi penyakit gastritis antara lain anemia pernesiosa, gangguan penyerapan vitamin B 12, penyempitan daerah antrum pylorus, gangguan penyerapan zat besi. Apabila di biarkan tidak terawat akan menyebabkan ulcus pepticus, 
perdarahan pada lambung, serta dapat juga menyebabkan kanker lambung terutama apabila lambung sudah mulai menipis ada perubahan selsel pada dinding lambung. Gasteritis ini dapat diatasi dan dicegah kekambuhanya dengan makan dengan jumlah kecil sedikit tapi sering, minum air putih untuk menetralkan asam lambung yang tinggi, dan mengkonsumsi makan makanan yang tinggi serat seperti buah dan sayur untuk memperlancar saluran pencernaan (Estefany, 2019).

Kejadian gastritis di Indonesia menurut WHO adalah $40,8 \%$ penderita gastritis. Kejadian gastritris di beberapa daerah di Indonesia cukup tinggi dengan prevalensi 274.396 kasus dari 238.452.952 jiwa penduduk. Berdasarkan profil kesehatan Indonesia 2013 sebanyak 30,154 kasus. Gastritis sering terjadi pada pelajar karena tidak memperhatikan pola makan akibat banyaknya kegiatan di kelas (Susilowati, 2018).

Menurut Rikesda 2013 angka kejadian gastritis di Jawa Tengah cukup tinggi yaitu 79,6\%. Gastritis kebanyakan menyerang pada usia remaja seperti mahasiswa dan siswa. Hasil wawancara 3 siswa SMU mengeluh sering merasakan sakit perut apabila terlambat makan, dan dari 5 siswa yang di wawancara 3 diantaranyamengalami tanda gejala gastritis tentunya sangat menganggu siswa dalam belajar. Berdasarkan uraian diatas, peneliti tertarik untuk meneliti identifikasi kejadian gastritis pada siswa SMU Muhammadyah 3 Masaran.

\section{TINJAUAN PUSTAKA}

\section{Definisi}

Gastritis akut merupakan inflamasi akut darididinding lambung terbatas pada mukosanya, sedangkan gastritis kronis inflamasi kronik terjadi dalam waktu yang lama pada permukaan lambung (Smeltzer \& Bare, 2002). Gastritis merupakan inflamasi pada mukosa lambung yang diakibatkan karena pola makan, yang ditandai dengan nyeri perut.

2. Etiologi

a. Gatritis akut disebabkan oleh faktor interna (kondisi pemicu yang menyebabkan pengeluaran asam lambung berlebihan) maupin faktor eksterna(menyebabkan iritasi dan infeksi) (Selfiana, 2015).

1). Faktor dari luar : makanan, diet yang salah, makanan banyak, terlalu cepat, makanan berbumbu yang dapat merusak mukosa lambung, seperti rempahrempah, alkohol, kopi, stres. Obat obatan digitalis, iodium, kortison, analgesik, anti inflamasi, bahan alkali yang kuat (soda).

2). Faktor dari dalam: toxin, bakteri yang beredar dalam darah misal morbili, difteri, variola. Infeksi pirogen langsung pada dinding lambung seperti streptococus, stapilococcus.

b. Gastritis kronis disebabkan oleh benigna atau maglinadari lambung atau oleh bakteri Helicobacter pylori (H.pylory) (Smeltzer \& Bare, 2002).

1). Tipe A (gastritis autoimun) seperti anemia

2). Tipe B (gastritis H. Pylori): faktor diet minum panas, pedas, alkohol, merokok, refluk isi usus kedalam lambung.

3. Manifestasi klinis

Tanda gejala gastritis menurut Smeltzer \& Bare (2002) meliputi:

a. Gastritis akut: ketidak nyamanan, sakit kepala, malas, mual, mutah, anoreksia.

b. Gastritis kronis: tipe A secara khusus asimtomatik. Tipe B pasien mengeluh anoreksia, nyeri ulu hati setelah makan, kembung, rasa asam di mulut, mual, mutah

Mukosa pada lambung mengalami pengikisan akibat konsumsi alkohol, obat anti inflamasi nonsteroid, infeksi helicobacter pylori. Pengikisan ini dapat menimbulkan peradangan. Inflamasi pada lambung juga dapat dipicu oleh peningkatan sekresi asam lambung, peningkatan sekresi asam lambung disebabkan oleh zat nikotin dalam rokok serta peningkatan rangsangan persarafan, seperti kondisi cemas, stress, dan marah. Peningkatan sekresi asam lambung dapat memicu rangsangan serabut aferen nervus vagus yang menuju medulla oblongata melalui komoreseptor yang banyak mengandung neurotransmitter epinefrin, serotonin sehingga lambung teraktivasi oleh rasa mual dan muntah (Ratu \& Adwan, 2013).

Mual dan muntah dapat mengakibatkan berkurangnya asupan nutrisi dan juga mengakibatkan penurunan cairan tubuh dan cairan dalam darah (hipovolemia). Kekurangan cairan merangsang pusat muntah untuk meningkatkan sekresi antidiuretic hormone (ADH) sehingga terjadi retensi cairan yang berlebihan (Ratu \& Adwan, 2013).

\section{METODE}

Metode penelitian yang digunakan adalah penelitian observasional deskriptif yaitu dilakukan peneliti pada saat memasuki situasi sosial tertentu sebagai obyek penelitian. pada tahap ini peneliti belum membawa masalah yang akan diteliti, maka peneliti ini melakukan penjelajahan umum dan menyeluruh, melakukan semua diskripsi yang di lihat, di dengar dan dirasakan (Sugiyono, 2010). Penelitian ini dilakukan di SMU Muhammadyah 3 
Masaran pada bulan Juli 2019. Populasi dalam penelitian adalah semua siswa SMU Muhammadyah 3 Masaran. Tehnik sample penelitian ini total sampling dimana seluruh anggota populasi dijadikan sampel, dengan kriteria inklusi sampel adalah sebagai berikut:

a. Aktif menjadi SMU Muhammadyah 3 Masaran

b. Usia remaja

c. Bersedia menjadi responden

Kriteria Eksklusi:

a. Tidak masuk saat di lakukan penelitian

Tahapan penelitian

a. Tahap persiapan

1) Pernyataan persetujuan menjadi responden penelitian.

2) Persiapan peneliti.

3) Menjelaskan tentang maksud dan tujuan penelitian kepada responden.

b. Tahap pelaksanaan

1) menyebarkan kuesioner

Instrumen yang digunakan adalah kuesioner tentang tanda gejala gastritis dan penyebab gastritis. Analisa data menggunakan deskreptif, dengan menghitung besaran jumlah dan prosentase. Setelah data dikumpulkan kemudian ditabulasikan dan disajikan dalam bentuk tabel.

HASIL DAN PEMBAHASAN

Penelitian ini dilaksanakan di SMA Muhammadyah 3 Masaran pada bulan Juli 2019 dengan cara mengisi kuesioner tentang gastritis. Besar sampel yang diambil sebanyak 52 responden sebagai subjek penelitian yang memenuhi kriteria yang telah ditentukan.

1. Gambaran Tempat Penelitian

SMA Muhammadyah 3 Masaran beralamat di jl. Raya Masaran Sragen, kelurahan Jati, Kecamatan Masaran, Kabupaten Sragen, terakreditasi A. Terletak berdekatan dengan SMK Muhammadyah 10 Masaran.

2. Karakteristik Responden

Karakteristik responden meliputi : gambaran umur, jenis kelamin pada responden siswa SMU Muhammadyah Masaran.

a. Karakteristik Responden Berdasarkan Umur Berikut ini di sajikan karakteristik responden berdasarkan umur

1. Tabel Distribsi Frekuensi Karakteristik Responden Berdasarkan

\begin{tabular}{ccc}
\hline $\begin{array}{c}\text { Karakteristik } \\
\text { Umur }\end{array}$ & $\begin{array}{c}\text { Jumlah } \\
\text { n }\end{array}$ & $\begin{array}{c}\text { Persen } \\
\text { \% }\end{array}$ \\
\hline 15 & 9 & 17,3 \\
16 & 19 & 36,5 \\
17 & 22 & 42,3 \\
18 & 1 & 1,9 \\
19 & 1 & 1,9 \\
\hline Total & 52 & 100 \\
\hline
\end{tabular}

(Sumber: Data primer, 2019).

Berdasarkan tabel diatas karakteristik responden usia sebagian besar berusia
17 tahun sebesar 22 responden (42,3\%)

b. Karakteristik Responden Berdasarkan Jenis Kelamin

berikut ini di sajikan karakteristik responden berdasarkan jenis kejamin

2. Tabel Distribusi Frekuensi Karakteristik Responden Berdasarkan Jenis

Kelamin

\begin{tabular}{|c|c|c|}
\hline $\begin{array}{l}\text { Karakteristik } \\
\text { Jenis Kelamin }\end{array}$ & $\underset{n}{\text { Jumlah }}$ & $\begin{array}{c}\text { Persen } \\
\%\end{array}$ \\
\hline Laki-laki & 3 & 5,8 \\
\hline Perempuan & 49 & 94,2 \\
\hline Total & 52 & 100 \\
\hline
\end{tabular}

(Sumber: Data primer, 2019).

Berdasarkan tabel diatas karakteristik responden sebagian besar berjenis kelamin perempuan sebesar 49 responden $(94,2 \%)$.

3. Identifikasi Kejadian Gastritis Pada Siswa SMU Muhammadyah 3 Masaran

Berikut ini menggambarkan frekuensi responden yang mengalami gastritis siswa SMU Muhammadyah 3 Masaran.

3. Tabel Identifikasi Kejadian Gastritis di Siswa SMU Muhammadyah 3 Masaran.

\begin{tabular}{lcc}
\hline $\begin{array}{c}\text { Kejadian } \\
\text { Gastritis }\end{array}$ & $\begin{array}{c}\text { Jumlah } \\
(\mathbf{n})\end{array}$ & $\begin{array}{c}\text { Persen } \\
(\%)\end{array}$ \\
\hline $\begin{array}{l}\text { Kejadian } \\
\text { Gastritis } \\
\text { Tidak }\end{array}$ & 27 & 51,9 \\
$\begin{array}{c}\text { mengalami } \\
\text { Gastritis }\end{array}$ & 25 & 48,1 \\
\hline \multicolumn{3}{l}{ Total } \\
(Sumber: Data primer, 2019).
\end{tabular}

Berdasarkan tabel diatas identifiakasi kejadian gastritis di SMU Muhammadyah 3 Masaran dari 52 responden yang mengalami gastritis sebanyak 27 responden $(51,9 \%)$.

1. Karakteristik Responden Pada Siswa SMU Muhammadyah 3 Masaran

Hasil penilitian karakteristik responden berdasarkan usia sebagian besar yang mengalami gastritis pada siswa SMU Muhammadyah 3 Masaran siswa berumur 17 tahun sebesar 22 responden $(42,3 \%)$. Hal ini sesui dengan penelitian Warguna (2016), sebagian besar yang mengalami gastritis pada siswa SMA di rentang usia 15-17 tahun. Menurut WHO itu termasuk usia remaja,berdasarkan asumsi peneliti dan hasil kuesioner yang disebarkan pada siswa SMU Muhammadyah 3 Masaran dimana siswa cenderung dituntut untuk mandiri sudah tidak teregantung orang tua, kebanyakan mengabaikan sarapan pagi, dll sehingga mudah terserang gastritis. 
Hasil penelitian menunjukan bahwa sebagian besar berjenis kelamin perempuan sebesar 49 responden $(94,2 \%)$. Hal ini sesuai pada penelitian Shalahuddin (2018), sebagian besar gastritis pada siswa SMU mengenai pada siswa perempuan. Gastritis terjadi banyak pada perempuan karena takut akan gemuk sehingga menjalankan diet, sehingga menghindari sarapan, makan siang atau bahkan makan hanya satukali dalam sehari, bahkan tidak makan sama sekali atau cukup dengan jajan di luar rumah. Kebiasaan siswa tersebut sebagai penyebab gastritis.

2. Identifikasi kejadian Gastritis Pada Siswa SMU Muhammadyah 3 Masaran

Kejadian gastritis di SMU Muhammadyah 3 Masaran dari 52 responden yang mengalami gastritis sebanyak 27 responden (51,9\%). Gastritis merupakan inflamasi pada lapisan lambung, yang ditandai dengan nyeri perut, bisa diakibatkan oleh gaya hidup seseorang. Hasil penelitian Warguna (2016), bahwa gastritis terjadi pada usia muda yaitu siswa SMK termasuk kategori usia produktif. Pada usia produktif merupakan usia dengan berbagai kesibukan, sehingga mudah terpapar faktor faktor yang dapat meningkatkan resiko untuk terkena gastritis. Resiko pola makan tidak teratur, stres, kebiasaan merokok, dan pola hidup yang tidak sehat akibat akibat aktivitas, kesibukan, dan pendidikan yang kurang.

Gastritis sering terjadi pada siswa dikarenakan stres, pola makan seperti makan makanan yang pedas asam, mengandung gas, jadwal makan yang tidak sesuai (Siska, 2017). Gastritis sering tidak di rasakan oleh para siswa, adanya tanda gejala tidak di rasakan. siswa tidak sarapan merupakan salah satu penyebab gastritis pada siswa.

Gastritis banyak di derita oleh siswa SMA yang tergolong remaja karena stres,

\section{DAFTAR PUSTAKA}

Estefany, D. 2019. 'Analisa Pola hidup Mahasiswa Di Perantauan Terhadap Gastritis'. Kedokteran UNS.

Monica, T. 2018. 'Hubungan antara Pengetahuan dan Tingkat Stres Terhadap Kekambuhan ulang gastritis Di Wilayah kerja Puskesmas Kota sungai Penuh Tahun 2018'. Menara Ilmu. Vol. XIII.

Muhith A, Siyoto S. 2016. 'Pengaruh Pola Makan Dan Merokok Terhadap Kejadian Gastritis Pada Lansia'. Jurnal Keperawatan. Vol. IX No 3. ISSN 1979-8091. makan tidak teratur, sehingga akan menganggu aktivitas sehari-hari siswa SMU (Rahmawati, 2019). Penyebab gastritis pada siswa SMU Muhammadyah 3 Masaran berdasarkan penelitian adalah pola makan dan mudah cemas. Pola makan seperti tidak pernah sarapan, makan yang tidak tepat waktu, makan tidak 3 x perhari, tidak membatasi makan makanan pedas dan asam. Pada siswa SMU kebanyakan tidak memperhatikan pola makan sehingga banyak yang menderita gastritis atau karena aktivitas yang padat menjadi pola makan tidak benar.

\section{KESIMPULAN}

1. Karakteristik responden usia sebagian besar berusia 17 tahun sebesar 22 responden (42,3\%). Jenis Kelamin sebagian besar berjenis kelamin perempuan sebesar 49 responden $(94,2 \%)$.

2. Kejadian gastritis di SMU Muhammadyah 3 Masaran dari 52 responden yang mengalami gastritis sebanyak 27 responden $(51,9 \%)$.

\section{SARAN}

1. Responden

Para siswa semakin tahu kejadian gastritis, penyebab dan tanda gejala sehingga dapat menghindari penyebab gastritis

2. Bidang keilmuan melakukan penelitian lain untuk pengembangan keilmuan misalnya pencegahan kekambuhan gastritis dengan pedidikan kesehatan pada siswa yang menderita gastritis.

3. Masyarakat bagi masyarakat yang mempunyai anak siswa smu memperhatikan penyebab gastritis sehingga dapat pencegah kekambuhan gastritis.

4. Peneliti Berikutnya melakukan penelitian faktor faktor penyebab gastritis pada siswa SMU

Rahmawati. 2019. 'Faktor faktor yang Berhubungan dengan Timbulnya Gastritis Pada Siswa Sekolah Menengah Kota Jambi'.

Ratu A, Adwan G M. 2013. Penyakit Hati, Lambung, Usus, dan Ambeien. Yogyakarta: Nuha Medika.

Rizky, I.I, Kepel, B,J, Kiling, M. 2019. 'Hubungan Penanganan Awal gastritis dengan Skala Nyeri Pasien UGD RS GMM Betheda' Tamahan. Vol 7 No $1 . \quad$ e-jurnal keperawatan.

Selviana, Berta, Yolanda. 2015. 'Effect Of Coffee And Stress With The Incidence Gastritis'. J Majority Jurnal. Vol.4. No. 2.

Shalahuddin, I, Rosidin, U. 2018. 'Hubungan Pola Makan Dengan Gastritis Pada Remaja di 
sekolah Menengah Kejuruan YBKP3

Garut'. Jurnal Kesehatan Bakti Tunas Husada. Vol. 18. No. 1.

Siska. 2017. 'Gambaran Pola Makan dalam Kejadian Gastritis Pada Remaja Di SMP N 1 Sekayan Kabupaten Sanggau'.

Smeltzer,.S,C\& Bare,.B,.B. 2002. Buku Ajar Keperawatan Medikal Bedah. Vol 2. Jakarta: EGC.

Sugiyono. 2010. Metodologi Penelitian Pendidikan (Pendekatan Kuantitatif, Kualitatif, Dan $R \& D)$. Bandung: Alfabeta.

Susilowati, L, Hariri MH. 2019. 'Hubungan Pola Makan Dengan Kejadian Gastritis Pada Pelajar X'. Jurnal antar Keperawatan.

Wahyu, A, Kusuma K, H, D, Andinawati, M. 2018. 'Hubungan Antara Kebiasaan Minim Minuman Keras (Alkohol) dengan Kejadian Gastritis Pada Remaja Akhir di Asramah Putra Papua Kota Malang'. Nursing News. Vol. 3. No 1.

Warguna, Retno, Hadi, Muhammad, Akoy, Tinny. 2016. 'Pengaruh Pendidikan Kesehatan Terhadap tingkat Pengetahuan Siswa Tentang Pencegahan Gastritis di SMA Kristen 3'. E-Jurnal Saputra. Volume 3. 